\title{
Crenças de eficácia de professores e motivação de adolescentes para aprender Física
}

\author{
Crenças de eficácia de professores
}

\author{
Alcides Goya \\ José Aloyseo Bzuneck \\ Sueli Édi Rufini Guimarães
}

\begin{abstract}
Resumo
Este trabalho teve por objetivo medir as crenças de eficácia de professores de física do ensino médio bem como a motivação dos seus alunos para aprender física. Para os 20 professores que formaram a amostra foi utilizado um questionário com 20 itens, em escala Likert, que avaliaram dois aspectos distintos das crenças: senso de eficácia pessoal e senso de eficácia do ensino. A 200 alunos das três séries do ensino médio foram aplicados questionários também com 20 itens, em escala Likert, que avaliaram sua motivação para aprender física e estratégias pessoais de estudo dessa disciplina. As escolas eram de três regiões geográficas distintas. Entre os professores, os escores médios nas crenças de eficácia pessoal foram significativamente mais altos do que os das crenças de eficácia do ensino. Além disso, as crenças de eficácia pessoal de professores relacionam-se positivamente com motivação dos alunos. Entre os alunos, variaram significativamente seus escores médios em função da turma a que pertencem, dentro de uma mesma série. Também foi significativa a relação positiva entre a motivação dos alunos e o uso de estratégias pessoais de estudo. Não houve diferenças significativas nesses escores nem em função das séries nem em função da localização geográfica da escola. Dos resultados foram extraídas indicações de estratégias motivacionais no ensino de física bem como sugestões de novas pesquisas que ampliem os conhecimentos na área.

Palavras chaves: crenças de eficácia de professores; motivação; Física.
\end{abstract}

\section{Teachers' self-efficacy beliefs and adolescents' motivation to learn physics}

\begin{abstract}
The aim of the present research was to assess physics teachers' self-efficacy beliefs in relation to adolescents' motivation and learning strategies used in middle school. A Likert questionnaire was applied to 20 teachers, which was designated to asses their personal efficacy and teaching efficacy beliefs. Two hundred students from three middle schools answered another Likert questionnaire about their motivation and personal strategies in the study of physics. Teachers and their students belonged to ten different schools in three different geographical areas. Among teachers, the scores in personal efficacy measures were higher than in teaching efficacy. In addition, only personal efficacy was positively related to students' motivation. Regarding the students, all measures varied significantly among different classes in the same grade, but no differences were found among grades or among schools. Significant relationships were found between motivation and study strategies in the whole sample and in every grade as well. Suggestions for motivation and teaching in middle school were drawn and for new studies in the area as well.
\end{abstract}

Keywords: teachers' effectiveness; motivation; Physics.

\section{Creencias de eficacia de profesores y motivación de adolescentes para aprender física}

\section{Resumen}

Este trabajo tuvo como objetivo medir las creencias de eficacia de profesores de física de la enseñanza secundaria, así como también la motivación de sus alumnos para aprender física. Para los 20 profesores que formaron la muestra fue utilizado un cuestionario con 20 ítems en escala Likert que evaluaron dos aspectos de las creencias: sentido de eficacia personal y sentido de eficacia de la enseñanza. Fueron aplicados cuestionarios también con 20 ítems, en escala Likert, a 200 alumnos de los tres grados de la enseñanza secundaria, que evaluaban su motivación para aprender física y estrategias personales de estudio de esa disciplina. Las escuelas eran de tres regiones geográficas distintas. Entre los profesores, las puntuaciones promedio en las creencias de eficacia personal fueron significativamente más altas que los promedios de las creencias de eficacia de enseñanza. Además de eso, las creencias de eficacia personal de los profesores se relacionan positivamente con la motivación de los alumnos. Entre los alumnos, los promedios de puntuaciones variaron significativamente en función de la sala a la cual pertenecen, dentro del mismo grado. También fue significativa y positiva la relación entre la motivación de los alumnos y el uso de estrategias personales de estudio. No hubo diferencias significativas en esas puntuaciones, ni en función de los grados ni en función de la localización geográfica de la escuela. De los resultados fueron extraídas tres indicaciones de estrategias de motivación en la enseñanza de física, así como también sugestiones de nuevas investigaciones que amplíen los conocimientos en el área.

Palabras clave: creencias de eficacia de profesores; motivación; Física. 
O presente estudo focaliza um aspecto da motivação de professores de física no ensino médio e a motivação de seus alunos para essa disciplina, juntamente com suas estratégias de aprendizagem.

A motivação tornou-se um problema de ponta em educação, quer se trate de professores como de alunos (Bzuneck, 2004). Um professor motivado, entusiasmado em sua atuação no ensino, tende mais facilmente a influenciar os seus alunos para um processo de aprendizagem eficaz. Por outro lado, professores desanimados, descomprometidos ou apáticos terão provavelmente alunos igualmente desmotivados, o que é intuitivamente plausível e, ao mesmo tempo, amplamente documentado na literatura contemporânea (por ex., Brophy, 1998; McCaslin \& Good, 1996; Patrick, Hisley \& Kempler, 2000). A esse respeito observou-se que a falta de motivação e interesse em professores e alunos podem contribuir para que estabeleça um círculo vicioso que mantém ambos em estado de "inércia" (Arruda, 2001).

O presente estudo contempla tanto a motivação de alunos como de professores. Por primeiro, aqui serão apresentados os conhecimentos acerca de um fator motivacional crítico em professores, que são suas crenças de auto-eficácia.

\section{As crenças de auto-eficácia dos professores}

$\mathrm{Na}$ definição de Bandura (1997), trata-se de “crenças nas próprias capacidades de organizar e executar cursos de ação necessários para produzir determinados resultados" (p. 3). Conceitualmente, elas não equivalem a autoconceito nem se confundem com outras formas de autopercepção de capacidade, que têm um caráter mais geral. Outros autores especificam adicionalmente que, quando se trata de professores, os cursos de ação a que se referem as crenças de auto-eficácia são aqueles "exigidos para realizarem com êxito uma tarefa de ensino, num dado contexto" (Tschannen-Moran, WoolfolkHoy \& Hoy, 1998, p. 233). Pajares (1997) explica que tais crenças atuam como filtros pelos quais novos fenômenos são interpretados e assim medeiam o comportamento subseqüente.

Uma quantidade considerável de pesquisas (para uma revisão ver, por exemplo, Azzi, Polidoro \& Bzuneck, 2006; Bzuneck, 2000; Pajares, 1997) tem revelado que as crenças de auto-eficácia têm influência direta na motivação dos professores e contribui significativamente para seu bem-estar pessoal no trabalho. Entre outros resultados, descobriu-se que aqueles que desenvolveram sólidas crenças de auto-eficácia revelam, em sua atuação docente, atitudes e comportamentos mais adaptadores, inclusive em circunstâncias mais adversas e em situações de mudanças curriculares. De modo geral, apresentam níveis mais elevados de comprometimento com o ensino; adotam procedimentos mais eficazes para lidar com alunos portadores de algum problema na aprendizagem; são mais propensos a introduzir práticas inovadoras; assumem uma postura mais democrática em classe, promotora de autonomia e confiança; e administram eficazmente fatores acadêmicos estressantes. Em síntese, crenças de auto-eficácia têm sido consistentemente associadas à motivação de professores e a melhores resultados de sua atividade docente. Woolfolk (1993) chegou a concluir que as crenças de eficácia dos professores representam um dos fatores que mais consistentemente têm sido relacionados ao desempenho dos alunos. Explica-se, por esse 
motivo, o crescente apreço entre pesquisadores da área educacional pelo estudo dessa variável (Graham \& Weiner, 1996), inclusive em nosso meio (Azzi \& Polydoro, 2006; Bzuneck, 1996, 2000; Fregoneze, 2000; Guimarães, 2003; Luppi, 2003).

As crenças de auto-eficácia dos professores, porém, variam em função dos contextos, das disciplinas, das turmas, bem como em função das fases da vida profissional (Taschannen-Moran \& cols., 1998). É que as crenças de auto-eficácia são o produto de certos fatores bem identificados. Em particular, pelo final da carreira docente, tais crenças aparecem cristalizadas e, no caso das crenças de eficácia do ensino em geral, mais marcadas pelo pessimismo (Bzuneck, 1996).

Bandura (1997), baseado em pesquisas, enumera quatro fatores com potencial de alimentar ou abalar essas crenças. O primeiro consiste nas experiências positivas de êxito em tarefas anteriores. Tal êxito propicia informação convincente de que a pessoa dispõe das capacidades necessárias para enfrentar desafios similares. O segundo fator são as experiências vicárias, cuja influência advém da observação de outras pessoas com êxito em situações similares. O terceiro fator é a persuasão verbal ou outras influências sociais que comunicam e convencem. O quarto fator são determinados estados fisiológicos que acompanham certos enfrentamentos. Entretanto, segundo demonstraram Tschannen-Moran e cols. (1998), nenhuma dessas quatro fontes terá influência direta na formação das crenças de auto-eficácia, mas todas elas dependem ainda de um processamento cognitivo de interpretação e avaliação tanto das próprias capacidades como da tarefa em questão.
Quando em psicologia se trata de construtos, um problema crítico consiste em sua avaliação ou mensuração. No caso da auto-eficácia de professores, que Tschannen-Moran e Hoy (2001) chegam a qualificá-la como um construto "escorregadio", a história das tentativas de sua avaliação tem mais de 20 anos e foi descrita em detalhes por Bzuneck e Guimarães (2003).

Entre os vários instrumentos desenvolvidos até o presente, Bzuneck (1996) traduziu para o português a escala de Woolfolk e Hoy (1990), aliás, fortemente tributária da proposta anterior de Gibson e Dembo (1984). Utilizando essa versão, Bzuneck e Guimarães (2003) aplicaram a análise fatorial exploratória às respostas de 422 professoras das quatro primeiras séries do Ensino Fundamental do sistema público de uma região paranaense. Os 20 itens da escala total apresentaram cargas fatoriais entre 0,38 e 0,67 e dois fatores distintos foram confirmados e correspondiam, respectivamente, à eficácia pessoal, com 12 itens (alpha $=0,73)$ e à eficácia do ensino, com oito itens (alpha $=0,70)$.

Os itens relativos à crença de eficácia pessoal focalizam as capacidades pessoais do professor e são apresentados afirmativamente, como neste exemplo: "tenho preparo suficiente para lidar com praticamente qualquer problema de aprendizagem". Neste caso, maiores índices de eficácia pessoal são revelados pela progressiva concordância com os itens apresentados.

Ao contrário, na avaliação da crença de eficácia de ensino os itens põem em destaque aspectos contextuais que afetam os professores em geral e, além disso, os itens são apresentados em forma negativa. Um exemplo de item dessa subescala é: "Se levarmos em conta todos os fatores os 
professores não representam uma influência poderosa sobre os alunos". Nessa avaliação, quanto maior for o índice de discordância com a alternativa tanto mais robusta seria a crença de eficácia. Podese razoavelmente concluir que os dois fatores regularmente encontrados nas pesquisas com esse instrumento representam aspectos distintos, porém não opostos, de um mesmo construto complexo (Morais \& Medeiros, 2005).

\section{A motivação do aluno e estratégias de aprendizagem}

A motivação é um construto, ou seja, não é algo diretamente observável, mas uma entidade "construída" pelos psicólogos para explicar a ocorrência dos comportamentos humanos. Além de ser um processo, motivação denota geralmente um fator ou fatores que levam a pessoa a agir e em determinada direção (Bzuneck, 2004). Como Stipek (1998) apontou, a motivação nos contextos de aprendizagem é detectável por meio de comportamentos observáveis dos alunos, que incluem iniciar prontamente uma tarefa, empenharse nela com esforço razoável e persistir apesar das dificuldades. A ausência de algum desses indicadores observáveis permite a inferência, embora com certa cautela, de falta de motivação.

Por que um aluno se torna motivado, ou como se explica sua desmotivação? Estas questões, de grande alcance prático, alinham-se com a observação de McCaslin e Good (1996) de que a motivação é um tema que tem ocupado lugar central nas discussões sobre o que vai mal em nossas escolas. Numa formulação conclusiva, quem estuda pouco aprende pouco e, por isso, prevê-se que terá um futuro comprometido sob vários aspectos. E aprender depende de motivação.

A literatura (por exemplo, Boruchovitch \& Bzuneck, 2004; Pintrich, 2003) tem apresentado as diferentes abordagens teóricas no estudo da motivação do aluno. Em particular, motivação intrínseca e motivação extrínseca, metas de realização, atribuições de causalidade figuram entre os mais importantes referenciais de pesquisas, com as quais se busca entender esse construto e extrair conclusões para a educação. No presente estudo, adotou-se a perspectiva de Brophy (1998) que, sem esboçar uma teoria específica, propôs que em sua atuação diária os professores devem: "buscar o desenvolvimento e a manutenção da motivação para aprender com as atividades acadêmicas. Isto é, devem fazer com que os alunos considerem tais atividades significativas e merecedoras de envolvimento, buscando obter com elas os benefícios de aprendizagem.” (p. 11-12).

A adolescência tem sido considerada uma fase crítica para a motivação escolar (Arruda, 2001; Boekaerts, 2003; Bzuneck \& Boruchovitch, 2003; Caldas \& Hübner, 2001; Legauld, Green-Demers \& Pelletier, 2006; Locatelli, 2004; Silva, 2004). Boekaerts (2003) propõe uma explicação para esse fenômeno, identificado em todo o ocidente, atribuindo-o à busca prevalente de objetivos de natureza social e de lazer pelos adolescentes e à cultura do consumo. Com tais preocupações, eles tendem a deixar os objetivos acadêmicos em "compasso de espera". Como conseqüência, os professores das últimas séries do ensino fundamental e de todo o ensino médio precisam desenvolver um conhecimento aprofundado sobre como lidar com a motivação desses alunos em suas 
respectivas disciplinas e, além disso, eles mesmos devem apresentar-se como altamente motivados em seu trabalho.

Ao terem como seu objetivo pessoal o domínio dos conteúdos, e não apenas concluir tarefas ou conseguir nota suficiente, os alunos irão aplicar esforço, investir tempo e energia psíquica em determinadas atividades mentais. Entre elas sobressai o uso de estratégias cognitivas e metacognitivas, que incluem desde métodos para se chegar à compreensão de um texto (como fazer resumos, esquemas, levantar questões) até o gerenciamento do tempo disponível para estudo (para uma descrição completa ver, por ex., Boruchovitch, 1999; Pintrich, 1989). Admite-se que algumas estratégias de aprendizagem o aluno desenvolve sozinho ao longo dos anos escolares. Porém, muitas delas, por serem mais complexas, precisam ser praticadas mediante ensino e treinamento específico e extensivo (Wood, Motz \& Willoughby, 1998). A literatura tem reiterado o que pesquisas descobriram: que sem estratégias adequadas de aprendizagem o estudo, mesmo inicialmente com motivação, pode resultar em fracassos que, por sua vez, acabarão por minar a própria motivação. Por isso, não é suficiente a preocupação com promover a motivação para aprender nos alunos, mas requer-se igualmente ensino, treinamento e cobrança de estratégias eficazes de aprendizagem (Boruchovitch, 1999; Bzuneck, 2001).

O presente estudo focalizou um dos componentes da motivação dos professores, que são suas crenças de auto-eficácia e sua relação com a motivação dos alunos. O recorte contemplou ainda a disciplina de física no ensino médio, em que os alunos são adolescentes. Tais especificidades atendem tanto a exigências de natureza teórica como a sugestões originadas de pesquisas. Segundo um modelo proposto por Tschannen-Moran e cols. (1998), é preciso identificar as tarefas de ensino e os contextos em que elas se desenvolvem. Neste sentido, além de pautar-se por uma teoria específica de motivação de professores, o estudo propõe-se aprofundar e ampliar as descobertas anteriores de Arruda (2001) e Silva (2004) que, com metodologia qualitativa, haviam investigado aspectos motivacionais de professores de física e de seus alunos e suas interações.

Como objetivos específicos, este trabalho pretendeu avaliar as crenças de auto-eficácia de professores de física no ensino médio e, em seus respectivos alunos, o grau de motivação para aprender física e o uso de estratégia pessoal de estudo nessa disciplina. Em segundo lugar, o estudo teve por objetivo analisar as relações entre os escores nas medidas de eficácia dos professores e as duas variáveis dos alunos, tomados todos como grupo e, adicionalmente, discriminadas as séries escolares e a localização geográfica das escolas.

\section{Método}

\section{Participantes}

Participaram da pesquisa 20 professores de física, onze homens e nove mulheres, e seus respectivos alunos do ensino médio de 10 escolas públicas de uma grande cidade da região Norte do Paraná. Da classe de cada professor, com 30 a 35 alunos, foram escolhidos aleatoriamente 10 alunos para responderem os questionários. Isso significa 
que de um total de 600 a 700 alunos chegou-se a um total de 200 para comporem a amostra. 60 eram do primeiro ano, 80 do segundo e 60 do terceiro ano. Do total de 20 turmas, 18 eram vespertinas e duas noturnas. Para a composição dessa amostra atendeu-se também ao critério de localização das escolas, sendo escolhidas duas da região central da cidade, quatro da região intermediária e quatro da periferia.

Todos os professores da amostra possuem Licenciatura em física e, com exceção de dois, também fizeram curso de especialização em ensino de física. Enquanto que quatro lecionam há menos de cinco anos, todos os demais têm experiência de magistério de até 15 anos, e três deles, com 16 anos ou mais.

\section{Instrumentos}

Dois tipos de questionários foram utilizados.

A avaliação das crenças de auto-eficácia dos professores deu-se por meio da escala de Woolfolk e Hoy (1990), cuja versão brasileira, como foi mencionada anteriormente, fora submetida a procedimentos estatísticos pelos quais se asseguraram suas propriedades psicométricas (Bzuneck \& Guimarães, 2003). O instrumento constou de 20 itens a serem respondidos numa escala Likert de cinco pontos, desde total concordância até inteira discordância.

A avaliação dos alunos quanto à sua motivação para física e ao uso de estratégias no seu estudo foi por meio de um questionário de 20 itens a serem respondidos também em escala Likert de cinco pontos. Esse instrumento fora organizado por Locatelli (2004) que, por sua vez, adaptou itens do Learning and Study Strategies Inventory - LASSI
(Weinstein, Palmer \& Schulte, 1987). A análise fatorial dessa versão, em estudo exploratório com adolescentes (Locatelli, 2004), confirmou que dos 20 itens, 13 convergiram para um fator subjacente que se denominou motivação para aprender e sete para outro fator, relativo a estratégias pessoais de estudo. Esses dois conjuntos foram utilizados neste estudo e, pelas respostas dos participantes, constatou-se uma homogeneidade entre os itens da variável motivação com alpha $=0,80$ e entre os itens de estratégias, alpha $=0,63$. São exemplos da categoria motivação: "Mesmo quando os conteúdos de física são bobos e desinteressantes, eu me dedico a aprender tudo até dar conta"; "quando decido estudar física, reservo um bom tempo para isso e não largo fácil". E exemplos de estratégias pessoais de estudo: "Costumo deixar para estudar física apenas nas vésperas das provas"; "quase para cada prova de física eu acabo estudando afobado, por causa do curto tempo", ambas a serem computadas em forma invertida, ou seja, marcação de concordância mais alta no enunciado indica estratégias menos adequadas de estudo, e viceversa.

A restrição ao estudo apenas da disciplina de física tem respaldo na sugestão de autores como Pintrich e DeGroot (1990), Ryan e Patrick (2001) que, entre outros, preconizam que os estudos sobre motivação de alunos devem atender às especificidades de cada disciplina. A física é considerada pelos professores e alunos, em geral, uma disciplina exigente, cujo conteúdo é extenso e sua compreensão supõe a capacidade de pensar abstratamente. Adicionalmente, nas escolas públicas da presente amostra, esta disciplina é ministrada em apenas duas aulas por semana, o que 
previsivelmente afeta a eficácia do trabalho dos professores.

\section{Procedimento}

A aplicação dos testes junto aos alunos foi efetuada pessoalmente pelo primeiro autor em 17 das 20 turmas pesquisadas. Nas três turmas restantes a aplicação foi feita por um aluno de especialização em Ensino de Física, devidamente treinado para a função. Toda a coleta de dados ocorreu no segundo semestre letivo, durante uma aula de física, com a colaboração do respectivo professor que, na ocasião, se retirava para outra sala onde respondia ao seu questionário específico. Muitos deles, porém, preferiram preenchê-lo com mais calma em outro momento e assim o devolveram posteriormente.

$\mathrm{Na}$ sala de aula, o aplicador expôs os objetivos da investigação e solicitou que, caso concordassem, os alunos manifestassem formalmente a aceitação de colaborar. Foi enfatizado que as respostas seriam anônimas e que o sigilo seria assegurado. $\mathrm{O}$ consentimento explícito em participar do estudo foi formalizado por todos os alunos e professores da amostra. Em cada classe, foram distribuídos os protocolos, porém apenas 10 alunos, escolhidos aleatoriamente, responderiam o questionário sobre motivação e estratégias. Os demais se ocuparam com responder a outro tipo de questionário com aparência similar, mas com outro conteúdo, cujos dados não fazem parte do presente estudo.

\section{Resultados}

Em atendimento aos objetivos deste estudo, primeiro serão expostos os dados descritivos com os escores médios grupais nas diversas medidas, tanto em relação aos professores como em relação aos alunos. Em seguida, serão apresentadas relações estatísticas entre as diferentes variáveis.

\section{Crenças de eficácia dos Professores de física}

A amostra dos 20 professores de física apresentou uma média de 3,82 $(D P=0,53)$ na variável Crença de eficácia pessoal e uma média de $2,68(D P=0,79)$ na crença de eficácia do ensino. O valor de correlação de Pearson entre essas duas médias foi zero, o que indica uma independência, mas não oposição, entre essas duas formas de crença. Além disso, a diferença entre as médias é significativa $(t=5,39, p=0,05)$, ou seja, aqueles professores, como grupo, mostram acreditar mais nas próprias capacidades de chegar a resultados positivos com seus alunos. Por outro lado, a análise de variância não encontrou diferença estatisticamente significativa entre as médias dos professores nas duas variáveis, quer em função das séries em que lecionam, quer em função da localização de suas escolas.

\section{Aspectos motivacionais dos alunos em relação à} física

Os escores médios em Motivação para aprender física foram similares entre os alunos das três séries do ensino médio investigadas. Nas seis turmas da primeira série, a média nessa variável foi 2,64 $(D P=0,63)$, nas oito segundas séries, a média foi 
2,67 e $(D P=0,72)$, e, nas seis turmas da terceira série, a média foi 2,68 e $(D P=0,65)$. A análise de variância aplicada às médias dessas três séries concluiu não serem significativas as diferenças entre as médias $(F=3,92 ; p=0,93)$. Entretanto, como esperado, entre as diversas turmas de cada série, foi significativa a diferença entre os escores médios nessa medida de motivação. Entre as médias das turmas de primeira série, $(F=3,56 ; p=0,00)$; entre as turmas da segunda série, $(F=5,05$; $p=0,00)$; e entre as turmas da terceira série, $(F=2,32 ; \quad p=0,05)$. Portanto, de cada série avaliada, não há homogeneidade entre as diferentes turmas quanto à motivação para aprender física.

Um padrão algo diferente foi descoberto em relação a Estratégias Pessoais do Estudo, teoricamente ligadas à motivação. Entre os alunos das três séries, foram estatisticamente superiores os escores médios da terceira série nessa variável $(M=3,30 ; D P=0,62)$, contra uma média de 2,95 e desvio padrão de 0,95 entre os da primeira série e 2,98 e desvio padrão de 0,75 entre os da segunda série.

Da análise de variância entre essas médias nos escores de estratégias surgiu um valor $F=3,92$ $(p=0,02)$ e o teste de Tukey definiu como estatisticamente superior a média entre os alunos da terceira série $(p=0,01)$ Quando, porém, se compararam os escores médios nessa medida de estratégias entre as diferentes turmas de cada série, novamente os resultados confirmaram uma heterogeneidade entre elas, como ocorreu com a medida de motivação. Entre as médias das turmas de primeira série, $(F=5,91 ; p=0,00)$; entre as turmas da segunda série, $(F=8,78 ; p=0,00)$; e entre as turmas da terceira série, $(F=4,22$; $p=0,00)$.

\section{Relações entre as diferentes medidas e amostras}

A Tabela 1 apresenta as correlações de Pearson entre as médias das quatro variáveis, duas das quais se referem às crenças de eficácia dos professores $(N=20)$ e as outras duas à motivação e uso de estratégias pelos alunos no seu todo $(N=200)$. Por essa estatística paramétrica, fica evidente que, embora tenha surgido, no caso dos professores, uma correlação nula entre a eficácia pessoal e a eficácia de ensino, foi bem alta entre os alunos a correlação.

Nota-se na Tabela 1, uma correlação de 0,83 entre a motivação para aprender física com as estratégias pessoais de estudo. Esta, aliás, foi a única correlação estatisticamente significativa. Observa-se aí também uma correlação moderada $(0,30)$ entre eficácia pessoal dos professores com a motivação dos alunos para aprender física e mais fraca com o uso de estratégias $(r=0,13)$. Mas foi negativa a correlação entre eficácia de ensino dos professores tanto com a motivação para aprender física dos alunos $(r=-0,31)$ como com o uso de estratégias $(r=-0,24)$.

Foram também discriminadas as séries escolares nas análises de correlação. A Tabela 2 mostra os diferentes valores de correlação.

Observa-se que, no caso dos alunos, é alta e significativa a correlação entre motivação e uso de estratégias nas três séries. Da mesma forma, mantém-se similar nas três séries a alta relação entre eficácia pessoal dos professores e motivação dos alunos para aprender física, ao mesmo tempo em que aumenta, com as séries, o valor da correlação negativa entre a crença de eficácia de 
ensino e a motivação para aprender e, mais ainda com o uso de estratégias.

Por fim, a Tabela 3 mostra as correlações entre as mesmas variáveis, considerada a localização geográfica das escolas. Observa-se nessa tabela a mesma tendência nos valores de correlação que aqueles encontrados na Tabela 2, ou seja, a distribuição geográfica das escolas não altera os valores das relações encontradas entre as variáveis em função das séries escolares.

Tabela 1. Correlações de Pearson entre as quatro variáveis observadas, considerada cada uma das duas amostras como um todo.

\begin{tabular}{|c|c|c|c|c|c|}
\hline & & EP & $\mathrm{EE}$ & MAF & EPE \\
\hline Professores & EP - Eficácia Pessoal & 1,00 & 0,00 & $-0,30$ & $-0,13$ \\
\hline$(N=20)$ & EE - Eficácia do Ensino & & 1,00 & $-0,31$ & $-0,24$ \\
\hline Alunos & MAF - Motivação para Física & & & $-1,00$ & $-0,83^{*}$ \\
\hline$(N=200)$ & EPE - Estratégias Pessoais de Estudo & & & & $-1,00$ \\
\hline
\end{tabular}

Tabela 2. Correlações de Pearson entre as quatro variáveis observadas, dentro de cada um das três séries do ensino médio.

\begin{tabular}{|c|c|c|c|c|c|c|c|c|c|c|c|c|}
\hline \multirow{2}{*}{ Variáveis } & \multicolumn{4}{|c|}{$1^{\circ}$ ano } & \multicolumn{4}{|c|}{$2^{\circ}$ ano } & \multicolumn{4}{|c|}{$3^{\circ}$ ano } \\
\hline & EP & $\mathrm{EE}$ & MAF & $\mathrm{EPE}$ & EP & $\mathrm{EE}$ & MAF & EPE & EP & $\mathrm{EE}$ & MAF & EPE \\
\hline EP & 1,0 & $-0,30$ & 0,30 & 0,26 & 1,0 & 0,13 & 0,34 & $-0,10$ & 1,0 & $-0,40$ & 0,24 & 0,34 \\
\hline $\mathrm{EE}$ & & 1,0 & $-0,18$ & $-0,01$ & & 1,0 & $-0,42$ & $-0,28$ & & 1,0 & $-0,46$ & $-0,83^{*}$ \\
\hline MAF & & & 1,0 & $0,94 * *$ & & & 1,0 & $0,83^{* *}$ & & & 1,0 & $0,86^{*}$ \\
\hline EPE & & & & 1,0 & & & & 1,0 & & & & 1,0 \\
\hline
\end{tabular}

$* p=0,05 ; * * p=0,01$

${ }^{1}$ Dos professores $\left(N=6\right.$ do $1 .^{\circ}$ ano; $N=8$ do $2 .^{\circ}$ e $N=6$ do $\left.3 .^{\circ}\right)$ : EP = eficácia pessoal; EE = eficácia do ensino. Dos alunos $\left(N=60\right.$ do $1 .^{\circ}$ ano; $N=80$ do $2 .^{\circ}$ e $N=60$ do $\left.3 .^{\circ}\right)$ : MAF = motivação para aprender física; EPE = estratégias pessoais de estudo.

Tabela 3. Correlações de Pearson entre as quatro variáveis observadas, no interior de cada uma das três regiões de localização das escolas.

\begin{tabular}{|c|c|c|c|c|c|c|c|c|c|c|c|c|}
\hline \multirow{2}{*}{ Variáveis } & \multicolumn{4}{|c|}{ Central } & \multicolumn{4}{|c|}{ Intermediária } & \multicolumn{4}{|c|}{ Periferia } \\
\hline & EP & $\mathrm{EE}$ & MAF & EPE & EP & $\mathrm{EE}$ & MAF & EPE & EP & $\mathrm{EE}$ & MAF & EPE \\
\hline EP & 1,0 & 0,14 & $-0,23$ & $-0,26$ & 1,0 & $-0,08$ & $0,69^{*}$ & 0,27 & 1,0 & $-0,36$ & 0,53 & 0,39 \\
\hline EE & & 1,0 & $-0,57$ & $-0,56$ & & 1,0 & $-0,05$ & $-0,02$ & & 1,0 & $-0,13$ & $-0,36$ \\
\hline MAF & & & 1,0 & $0,89 * *$ & & & 1,0 & $0,82 * *$ & & & 1,0 & 0,57 \\
\hline EPE & & & & 1,0 & & & & 1,0 & & & & 1,0 \\
\hline
\end{tabular}

$* p=0,05 ; * * p=0,01$

${ }^{1}$ Dos professores $(N=7$ da região central; $N=8$ da região intermediária e $N=5$ da periferia): EP = eficácia pessoal; EE = eficácia do ensino. Dos alunos $(N=70$ da região central; $N=80$ da região intermediária e $N=50$ da periferia): MAF $=$ motivação para aprender física; EPE = estratégias pessoais de estudo. 


\section{Discussão}

Foi objetivo principal de este estudo investigar aspectos definidos da motivação tanto de professores de física no ensino médio como de seus respectivos alunos. Em estudos anteriores também com alunos de física, Arruda (2001) e Silva (2004) haviam identificado sérios problemas de motivação em suas amostras. Como a motivação de alunos é um construto complexo e, ao mesmo tempo, resultado da convergência de diversos fatores, cada estudo é compelido a restringir-se à apreciação de algumas variáveis selecionadas, sob inspiração de uma teoria específica. Foram aqui avaliadas as crenças de eficácia de uma amostra de professores de física no ensino médio de escolas públicas. Para que se avaliem os resultados do presente estudo, deve-se ter presente que, de acordo com TschannenMoran e cols. (1998), esse tipo de crença depende do julgamento que um professor faz de suas capacidades ou recursos internos e, ao mesmo tempo, da percepção das exigências de sua função, num contexto determinado. As duas subescalas de mensuração usadas nesta pesquisa, com propriedades psicométricas bem definidas pela análise fatorial, contemplaram justamente esses dois aspectos e trouxeram resultados similares ao de outros estudos anteriores. Isto é, na avaliação da crença de eficácia pessoal (EP), que contém itens relativos ao julgamento das próprias capacidades, a média grupal dos professores da amostra foi bem superior ao ponto médio e, estatisticamente, mais elevada que a média na subescala de percepção da eficácia do ensino (EE), que focaliza as dificuldades do contexto. As altas médias na medida de eficácia pessoal significam uma avaliação altamente positiva das próprias capacidades para ser professor de física. Os itens dessa escala começam com frases do tipo "eu posso", "eu consigo" e semelhantes.

À parte uma possível influência de viés autoprotetor nesse julgamento, há elementos que contribuem objetivamente para sua retidão. Os professores da presente amostra possuem, quase na sua totalidade, grau de especialização em ensino de física e, além disso, lecionam há vários anos. Segundo Bandura (1997), a experiência de êxito é a primeira e mais decisiva fonte de alimentação das crenças de auto-eficácia. No caso do presente estudo, o êxito dos professores não foi aferido pelo grau de aprendizagem dos alunos, mas é razoável admitir-se uma experiência de êxito pessoal em função do domínio dos conteúdos e da segurança em trabalhar o currículo, conquistada ano após ano em sala de aula. Há pesquisas que concluíram que, com a experiência no ensino, os professores desenvolvem um senso de eficácia relativamente estável (Tschannen-Moran \& cols., 1998).

Portanto, no aspecto da auto-avaliação das capacidades pessoais, com base em suas respostas aos itens da respectiva subescala, os professores da presente amostra revelam dispor de um esteio seguro para continuar trabalhando, ou seja, sua motivação pelo ensino de física estaria bem nutrida. Mas este é apenas um componente motivacional ligado à auto-eficácia, que precisa ainda ser complementado pela apreciação simultânea das exigências contextuais explicitadas na outra subescala, a de eficácia do ensino.

Antes, porém, é necessário descobrir o significado de um escore médio significativamente mais baixo na medida de eficácia do ensino, que 
põe em destaque os empecilhos à eficácia docente, originados sobretudo do ambiente familiar. É como se, nessa subescala, cada item lembrasse em que contexto desfavorável os professores têm que atuar.

Pajares (1997) e Tschannen-Moran e cols. (1998) haviam questionado justamente sobre qual seria a melhor interpretação desses dois fatores que têm continuamente surgido nas medidas quantitativas de eficácia. Não se deve concluir pela existência de uma contradição entre os resultados nas duas subescalas e nem mesmo por uma simples justaposição de resultados distintos e desconexos. Pelo contrário, como Morais e Medeiros (2005) sugeriram, essas duas subescalas representam aspectos distintos e complementares de um mesmo construto complexo, e que estariam dispostos nos extremos de um mesmo continuum. Tal conclusão afina-se com o próprio conceito de auto-eficácia, que se refere simultaneamente à avaliação das próprias capacidades frente a instâncias contextuais explicitadas e bem definidas. Dessa forma, em relação às suas crenças de auto-eficácia, com base nas medidas aqui empregadas, os professores da presente amostra têm um perfil psicológico composto de crenças bem robustas de auto-eficácia pessoal e, ao mesmo tempo, de crenças mais atenuadas quando focalizaram os professores em geral e as dificuldades contextuais do ensino em nosso meio. A consideração dessas contingências teria acarretado o julgamento mais negativista quanto à possibilidade da classe dos professores darem conta de sua tarefa de ensino, ou seja, de conseguirem os resultados desejados. Convém lembrar que uma condição desfavorável identificada nas escolas da presente amostra consiste em os professores terem que dar conta de um conteúdo conhecidamente extenso e complexo de física, em cada série, com apenas duas aulas por semana.

Em segundo lugar, o presente estudo propôs-se investigar as associações entre as crenças de eficácia dos professores e a motivação e estratégias de seus alunos de física. A busca por tais associações seria uma resposta à questão educacional do significado prático daquelas crenças, como foi demonstrado pela literatura até o presente (ver, por exemplo, Bzuneck, 2000). Isto é, em que medida as crenças de eficácia dos professores da presente amostra influenciam o seu próprio comportamento e o de seus alunos no aspecto motivacional e no uso de estratégias de estudo.

As análises estatísticas aqui adotadas são de natureza correlacional, que por sua natureza não permitem inferências causais. Entretanto, correlações, quer sejam positivas ou negativas, sempre sugerem algum tipo de influência numa determinada direção, ou mais provavelmente recíproca. Assim, descobriu-se no presente estudo que as crenças de eficácia pessoal dos professores se relacionam positivamente com a motivação para física e, em menor grau, com o uso de estratégias de estudo. As crenças na eficácia do ensino relacionam-se negativamente com essas duas variáveis. Com base em toda a literatura pertinente, poder-se-ia concluir que há pelo menos uma influência recíproca positiva. Professores motivados, porque acreditam em suas capacidades, têm alunos motivados; por seu turno, alunos motivados e que, por isso, são aplicados alimentam a motivação e as crenças de eficácia de seus 
professores. Entretanto, a correlação encontrada é apenas moderada, o que ainda precisa ser explicado.

A motivação do aluno resulta de muitos fatores e, mesmo por parte do professor, não bastam sua competência e a crença em suas capacidades para que o aluno se sinta motivado por uma dada disciplina. No presente estudo, a motivação para física variou significativamente entre as diferentes turmas de cada série, o que pode ser em parte atribuído a diferenças nos modos de seus professores lidarem com a turma, em seu respectivo contexto. Ao menos dois tipos de estratégias motivacionais, preconizadas na literatura descrita por Guimarães (2004a), podem ser aqui avocadas a título de exemplo, para uma interpretação adequada desses resultados.

Em primeiro lugar, em que medida e com que freqüência os professores de física mostram o valor e a relevância de seus conteúdos, especialmente em termos de sua utilidade prática? Ter bem claro para quê serve estudar certo conteúdo tem forte apelo motivacional para todo aluno. Um dado revelador neste estudo é que o emprego de estratégias de estudo apareceu com escores significativamente mais altos entre os alunos da terceira série. A proximidade do vestibular poderia ter sido o incentivo para esse maior envolvimento cognitivo no estudo de física, e isso presumivelmente seria explicitado em verbalizações dos professores, o que não estaria acontecendo nas séries anteriores, nas quais não se ouviria nem essa nem outra forma de argumentação pela relevância da disciplina de física. Evidentemente, trata-se de uma hipótese explicativa, que pesquisas específicas poderiam contemplar um dia.
Há uma outra razão que estaria por detrás daquele nível apenas moderado de correlação entre a eficácia pessoal dos professores e a motivação dos alunos. Tal motivação, tanto no ensino fundamental como no médio, é decididamente influenciada por certo tipo de relacionamento pessoal do professor com seus alunos. Guimarães (2004b) apresenta uma literatura contemporânea que tem focalizado para a motivação o papel de vínculos afetivos ou do acolhimento que o professor deve nutrir em classe. Pode-se razoavelmente questionar se professores de ciências em geral, conscientes de suas capacidades e conhecimentos, atendem à necessidade de vínculo que todo aluno tem. Além disso, é bem previsível que o contato com uma classe relativamente numerosa, num bloco de apenas duas aulas por semana, não facilite uma aproximação mais afetiva com seus alunos, mas que, pelo contrário, favoreça uma forma de ensino impessoal e mais burocrático, ou seja, centrado exclusivamente nos conteúdos e nas avaliações.

Em suma, ao se considerarem as crenças de eficácia dos professores como uma variável crítica, elas seriam fator necessário, mas não suficiente, para alimentar e manter a própria motivação dos alunos. Entre outras exigências, o professor deve esmerar-se por sempre mostrar à sua classe o valor e relevância pessoal dos conteúdos de aprendizagem e primar por relacionamentos pessoais positivos de acolhimento e atenção.

Merece comentário o resultado de que entre todos os alunos das três séries foi alta e significativa a relação entre sua motivação para física e o emprego de estratégias de estudo. Índices semelhantes verificaram-se entre alunos tanto da região central como da região intermediária. Quanto 
aos alunos da periferia, a correlação entre aquelas variáveis foi menos alta e sem atingir o nível de significância estatística, o que pode ser atribuído à amostra menos numerosa dessa região. Vale, porém, relativamente a todos os alunos da presente amostra, a conclusão geral de que, na medida em que estiverem motivados, também se esmeram em gerenciar seu tempo e outras condições de estudo que favoreçam a aprendizagem. Esses resultados alinham-se com os de outros, também com adolescentes do ensino médio, descritos na literatura (ver, por exemplo, Greene, Miller, Crowson, Duke \& Akey, 2004; Locatelli, Bzuneck \& Guimarães, 2007), confirmando a estreita associação entre motivação e uso de estratégias eficazes de aprendizagem.

Um requisito prévio para o uso habitual de estratégias eficazes de aprendizagem é que os alunos as conheçam. O presente estudo encerra a limitação de que os itens da subescala de estratégias focalizavam apenas aspectos gerenciais, que são importantes e que se presume serem conhecidos de todos. Mas convém aqui lembrar que, nas aprendizagens escolares, outras estratégias cognitivas e metacognitivas precisam ser dominadas e postas em prática nos estudos diários. O fracasso escolar de estudantes brasileiros, causado por falta de estratégias eficazes de aprendizagem, tem sido bem apontado na literatura (Boruchovitch, 1999; Bzuneck, 2001). Wood e cols. (1998) são enfáticos em cobrar de professores o cumprimento da tarefa de ensinar e treinar os alunos no uso de estratégias mais avançadas, uma tarefa que não isenta professores de física no ensino médio, se pretenderem êxito e motivação de seus alunos nessa disciplina.

\section{Limitações e sugestões de novos estudos}

É preciso reconhecer que o presente estudo sofre de algumas limitações ocasionadas, sobretudo pelos recortes a que deve ater-se toda pesquisa de campo. Daí, porém, derivam sugestões para que novas pesquisas dêem continuidade na busca de um conhecimento mais completo na área em questão.

Em primeiro lugar, deve ficar bem claro que, no presente caso, não foi objetivo avaliar de modo abrangente toda a motivação daqueles professores de física, mas apenas um dos fatores críticos dessa variável, reconhecidamente não o único. Há professores vocacionados e apaixonados, intrinsecamente motivados pelo ensino, mas nem todos são assim. Em acréscimo, fatores sócioambientais diversos que, de resto, afetam de diversas maneiras as próprias crenças de eficácia, podem ter outros efeitos diferenciados sobre a motivação dessa categoria. Lembre-se, particularmente, a relevância de se sentirem respeitados pelos alunos e valorizados pelos poderes públicos e administradores, o que inclui a questão salarial. Portanto, os presentes dados não fornecem mais do que um dos componentes da motivação de professores de adolescentes.

As descobertas acerca da motivação dos professores, enquanto derivada de suas crenças de eficácia, sugerem que, para uma compreensão completa de seu significado educacional, a investigação incluísse igualmente seus comportamentos em classe, mesmo que aferidos por meio de relatos verbais. Isto é, um passo importante seria agora buscar saber como agem os professores de física, com tal ou tal nível de crenças de eficácia, nas circunstâncias em que devem atuar junto a 
adolescentes no ensino médio, em função das características de cada escola e de cada classe.

Por último, importa reconhecer no presente estudo uma limitação que concerne à amostra relativamente reduzida de professores. Embora pudesse ser trabalhada como um grupo único em certas análises, a distribuição por séries reduziu a números que podem comprometer as comparações estatísticas. Mas, a se persistir com uma metodologia quantitativa, cabe a sugestão de se conduzir mais estudos com grandes amostras de professores de física e sempre com alunos de cada série do ensino médio. Uma coisa é a condição dos alunos das duas primeiras séries e seus respectivos professores, outra coisa é a daqueles que estão às vésperas de um possível vestibular. $\mathrm{Na}$ mesma linha, seria oportuno investigar nesses alunos suas percepções acerca da validade de estudar os conteúdos de física que lhes são ministrados, em conjunção com suas possíveis aspirações vocacionais, seguindo a esteira de Locatelli (2004). Foi confirmado por essa autora que a perspectiva de tempo futuro por parte de adolescentes afeta sua motivação por uma dada disciplina.

Em suma, as descobertas do presente estudo parecem contribuir para a compreensão da motivação de professores e alunos de física, uma área ainda carente de pesquisas nacionais. Por outro lado, as limitações apontadas acima abrem caminho para o delineamento de outras pesquisas que ampliem e produzam aprofundamento dos conhecimentos dos aspectos motivacionais no contexto escolar.

\section{Referências}

Arruda, S. M. (2001). Entre a inércia e a busca: reflexões sobre a formação em serviço de professores de física do ensino médio. Tese de Doutorado em Educação, Universidade de São Paulo, São Paulo.

Azzi, R. G., \& Polydoro, S. A. J. (2006). Auto-eficácia em diferentes contextos. Campinas: Alínea.

Azzi, R. G., Polydoro, S. A. J., \& Bzuneck, J. A. (2006). Considerações sobre a auto-eficácia docente. Em R. G. Azzi \& S. A. J. Polydoro (Orgs.), Auto-eficácia em diferentes contextos (pp. 149-159). Campinas: Alínea.

Bandura, A. (1997). Self-efficacy: the exercise of control. New York: W.H. Freeman.

Boekaerts, M. (2003). Adolescence in dutch culture: A self regulative perspective. Em F. Pajares \& T. Urdan (Eds.), International Perspectives on Adolescence (pp. 99-122). Greenwich, Conn.: Information Age Publishing.

Boruchovitch, E. (1999). Estratégias de aprendizagem e desempenho escolar: Considerações para a prática educacional. Psicologia: Reflexão e Crítica, 12(2), 361367.

Boruchovitch, E., \& Bzuneck, J. A. (Orgs.). (2004). A Motivação do aluno: contribuições da psicologia contemporânea. ( $3^{\mathrm{a}}$ ed.). Petrópolis: Vozes.

Brophy, J. (1998). Research on motivation in Education: Past, present, and future. Em T. Urdan (Ed.). Advances in Motivation and Achievement: Achievement Contexts (Vol. 11, pp.1-44). Greenwich, CT: JAI Press.

Bzuneck, J. A. (1996). Crenças de auto-eficácia de professoras do primeiro grau e sua relação com variáveis de predição e de contexto. Arquivos Brasileiros de Psicologia, 48, 67-89. 
Bzuneck, J. A. (2000). As crenças de auto-eficácia dos professores. Em F. F. Sisto, G. C. Oliveira \& L. D. T. Fini (Orgs.), Leituras de Psicologia para Formação de Professores (pp. 117-134). Petrópolis: Vozes / Bragança Paulista: Universidade São Francisco.

Bzuneck, J. A. (2001). O Esforço nas aprendizagens escolares: Mais do que um problema motivacional do aluno. Revista Educação e Ensino-USF, 6, 7-18.

Bzuneck, J. A. (2004). A motivação do aluno: aspectos introdutórios. Em E. Boruchovitch \& J. A. Bzuneck (Orgs.), A Motivação do Aluno: Contribuições da Psicologia Contemporânea (pp. 9-36). Petrópolis: Vozes.

Bzuneck, J. A., \& Boruchovitch, E. (2003). Adolescence and education: contemporary trends in brazilian research. Em F. Pajares \& T. Urdan (Eds.), International Perspectives on Adolescence (pp. 215-236). Greenwich: Information Age Publishing.

Bzuneck, J. A., \& Guimarães, S. E. R. (2003). Crenças de eficácia de professores: validação da escala de Woolfolk e Hoy. Psico-USF, 8, 137-143.

Caldas, R. F. L., \& Hübner, M. M. C. (2001). O desencantamento com o aprender na escola: o que dizem professores e alunos. Psicologia: Teoria e Prática, 3, 71-82.

Fregoneze, G. B. (2000). Crenças de auto-eficácia de professores em situação de alterações curriculares no ensino médio. Dissertação de Mestrado em Educação, Universidade Estadual de Londrina, Londrina, Paraná.

Gibson S., \& Dembo, M. H. (1984). Teacher efficacy: A construct validation. Journal of Educational Psychology, $76,569-582$.

Graham, S., \& Weiner, B. (1996). Theories and principles of motivation. Em D. C. Berliner \& R. C.
Calfee (Eds.), Handbook of Educational Psychology (pp. 63-84). New York: Simon \& Schuster Macmillan.

Greene, B. A., Miller, R. B., Crowson, H. M., Duke, B. L., \& Akey, K. (2004). Predicting high school students cognitive engagement and achievement: Contributions of classroom perceptions and motivation. Contemporary Educational Psychology, 29, 462-482.

Guimarães, S. E. R. (2003). Avaliação do estilo motivacional do professor: adaptação e validação de um instrumento. Tese de Doutorado em Educação, Universidade Estadual de Campinas, Campinas, São Paulo.

Guimarães, S. E. R. (2004a). A organização da escola e da sala de aula como determinantes da motivação intrínseca e da meta aprender. Em E. Boruchovitch \& J.

A. Bzuneck (Orgs.), A Motivação do aluno: Contribuições da psicologia contemporânea (pp. 78-95). Petrópolis: Vozes.

Guimarães, S. E. R. (2004b). Necessidade de pertencer: Um motivo humano fundamental. Em E. Boruchovitch \& J. A. Bzuneck (Orgs.), Aprendizagem: Processos psicológicos e o contexto social na escola (pp.177-199). Petrópolis: Vozes.

Legault, L., Green-Demers, I., \& Pelletier, L. (2006). Why do high school students lack motivation in the classroom? toward an understanding of academic a motivation and the role of social support. Journal of Educational Psychology, 98, 567-582.

Locatelli, A. C. D. (2004). A perspectiva do tempo futuro como um aspecto da motivação do adolescente na escola. Dissertação de Mestrado em Educação, Universidade Estadual de Londrina, Londrina, Paraná.

Locatelli, A. C. D., Bzuneck, J. A., \& Guimarães, S. E. R. (2007). A motivação de adolescentes em relação com 
a perspectiva de tempo futuro. Psicologia: Reflexão $e$ Crítica, 20 (no prelo).

Luppi, M. A. R. (2003). Crenças de auto-eficácia de Professores em ambientes de trabalho acentuadamente adversos. Dissertação de Mestrado em Educação, Universidade Estadual de Londrina, Londrina, Paraná.

McCaslin, M., \& Good, T. L. (1996). The informal curriculum. Em D. C. Berliner \& R. C. Calfee (Eds.), Habdbook of Educational Psychology (pp. 622-670). New York: Simon \& Schuster Mac Millan.

Morais, F., \& Medeiros, M. T. (2005). Desenvolvimento profissional do professor: A auto-eficácia e as representações dos factores do contexto escolar. Revista Portuguesa de Pedagogia, 39, 145-168.

Pajares, F. (1997). Current directions in self-efficacy research. Em M. L. Maehr \& P. H. Pintrich (Eds.), Advances in motivation and achievement (pp. 1-49). Greenwich: JAI Press.

Patrick, B. C., Hisley, J., \& Kempler, T. (2000). "What's everybody so excited about?": The effects of teacher enthusiasm on student intrinsic motivation and vitality. The Journal of Experimental Education, 68, 217-238.

Pintrich, P. R. (1989). The dinamic interplay of student motivation and cognition in the college classroom. Em M. L. Maehr \& C. Ames (Eds.), Advances in motivation and achievement. Vol. 6: Motivation enhancing environments (pp.117-160). Greenwich: JAI Press.

Pintrich, P. R. (2003). A motivational science perspective on the role of student motivation in learning and teaching contexts. Journal of Educational Psycholoy, 95, 667-686.

Pintrich, P. R., \& De Groot, E. V. (1990). Motivational and self-regulated learning components of classroom academic performance. Journal of Educational Psychology, 82, 33-40.

Ryan, A. M., \& Patrick, H. (2001). The classroom social environment and changes in adolescents' motivation and engagement during middle school. American Educational Research Journal, 38, 437-460.

Silva, E. L. (2004). Aspectos motivacionais em operação nas aulas de física do ensino médio, nas escolas estaduais de São Paulo. Dissertação de Mestrado em Educação, Universidade de São Paulo, São Paulo, São Paulo.

Stipek, D. (1998). Student motivation: From theory to practice. Englewood Cliffs: Prentice Hall.

Tschannen-Moran, M., \& Hoy, A. W. (2001). Teacher efficacy: capturing an elusive construct. Teaching and Teacher Education, 17, 783-805.

Tschannen-Moran, M., WoolfolkHoy, A. W., \& Hoy, W. K. (1998). Teacher efficacy: Its meaning and measure. Review of Educational Research, 68, 202-248.

Weinstein, C. E., Palmer, D. R., \& Schulte. A. C. (1987). Learning and Study Strategies Inventory - Lassi. Clearwater: H \& H Publishing Company, Inc.

Wood, E., Motz, A., \& Willoughby, T. (1998). Examining students' retrospective memories of strategy development. Journal of Educational Psychology, 90, 698-704.

Woolfolk, A. (1993). Developing a sense of efficacy in begining teachers. Allyn \& Bacon Educator's Forum, 3, 73-82.

Woolfolk, A. E., \& Hoy, W. K. (1990). Prospective teachers' sense of efficacy and beliefs about control Journal of Educational Psychology, 82, 81-91. 
Recebido em: 26/06/2007

Revisado em: 04/05/2008

Aprovado em: 04/06/2008

Sobre os autores:

Alcides Goya (alcidesgoya@hotmail.com) é Doutor em Física pelo Instituto de Física da UnB e atualmente é Professor na Universidade Tecnológica Federal do Paraná, em Cornélio Procópio.

José Aloyseo Bzuneck (bzuneck@sercomtel.com.br) é Doutor em Ciências - Psicologia do Escolar, pelo Instituto de Psicologia da USP e atualmente é Professor Sênior da Universidade Estadual de Londrina.

Sueli Édi Rufini Guimarães (sueli_rufini@ @otmail.com) é Doutora em Educação pela UNICAMP e atua no Programa de Pós-Graduação em Educação na Universidade Estadual de Londrina. 